\title{
Sociobiology
}

REVIEW

\section{Emerging Vistas of Remote Sensing Tools in Pollination Studies}

\author{
V KRISHNASAMY ${ }^{1}$, R SUNDARAGURU², U AMALA ${ }^{3}$ \\ 1 - Associate Professor, ECE Department, CMR Institute of Technology, Bengaluru, Karnataka, India \\ 2 - Professor \& Head, ECE Department, Sir. M. Visvesvaraya Institute of Technology, Bengaluru, Karnataka, India \\ 3 - Scientist (Entomology), Division of Germplasm Conservation and Utilization. ICAR-National Bureau of Agricultural Insect Resources, \\ Bengaluru, Karnataka India
}

\section{Article History}

\section{Edited by}

Kleber Del-Claro, UFU, Brazil

Received

24 November 2018

Initial acceptance

Final acceptance

Publication date

11 June 2019

18 July 2019

14 November 2019

\section{Keywords}

LiDAR; pollinators; remote sensing; sensors; unmanned aerial vehicles.

\section{Corresponding author}

Venkateswaran Krishnasamy

Associate Professor, Department of

Electronics and Communication

CMR Institute of Technology, 132

AECS Layout, ITPL Main Road

Kundalahalli, Bengaluru 560037, India.

E-Mail:vvenkates05@gmail.com

\begin{abstract}
With the growth of information and technology across the globe, remote sensing applications find a place in the ecological studies of pollinators. The utilization of remote sensing tools in understanding the ecosystem services rendered by the bee pollinators is reviewed here. We discussed how radar and radio telemetry techniques help to track individual bees, their foraging behaviour and density in relation to altered phenology of flowering crops in a landscape. Satellite imagery tools represent a set of techniques used to assess landscape affected by anthropogenic factors that directly influence pollination ecology of bees. Habitat modelling data were generated using tools like Moderate Resolution Imaging Spectroradiometer to monitoring invasive bee species that cause a threat to native bee fauna. We explained the utilization of unmanned aerial vehicles to map the floral resources that influence the density and incidence of pollinators. Remote sensing tools were used to measure sequences of pollination events.
\end{abstract}

\section{Introduction}

Pollination is the processes of transfer of pollen from the male to female flower being aided by insects as a major share although different agents like wind, water also play their role in pollination. Around $35 \%$ of pollination process was reported to be directly dependent upon insects for pollination (Klein et al., 2007; Ollerton et al., 2011). Bees are an important group of pollinators playing a vital role in the pollination, fruit and seed set of economically important agricultural crops (Kremen et al., 2007). Securing these essential and valuable pollination services by the bees is vital to achieve food security, preservation of biodiversity in agro-ecosystems (Peh \& Lewis, 2012; Winfree, 2013). Bee decline is a global crisis as negatively influenced by indiscriminate usage of pesticides, loss of their natural habitats, spread of pests and pathogens and by invasive species (Brown et al., 2009; Potts et al., 2010). There is an immense need to conserve the bees for the valuable pollination service and to retain their diversity in native ecosystem. Native bees being efficient pollinators with vast majority of them of ground nesting habit making their domestication and conservation a difficult phenomenon (Rader et al., 2013). Bees being active fliers and rapidly mobile in cropping ecosystem, traditional field observations are cumbersome to study their foraging behaviour in different crops (Kimura et al., 2014). Remote sensing tools were widely employed for its manless interventions in studying the movement, range and distribution of pollinators and floral traits.

Remote sensing is defined as the method of measuring an object or phenomenon without having a physical contact through the detection of reflected or emitted electromagnetic energy (Mulla, 2013). Remote sensing can provide space and time efficient observations and could be widely used in 
studying the ecosystem services rendered by the pollinators. This tool is widely employed in mapping vegetation structure, pest and disease monitoring, distribution of invasive or threatened species, measuring and monitoring biodiversity and to assess habitat suitability (Dong et al., 2003; Diao \& Wang, 2014). The present paper discusses the application of potential remote sensing tools used in pollinator ecology studies, such as mapping of floral habitats with pollinator abundance, tracking of bees to study invasive species in the target area, quantification of vegetation cover to understand the foraging behaviour of bees and tools used to predict pollination services in crops.

\section{Radio telemetry in tracking bees}

The major challenge in utilization of solitary bees is their domestication. The vast majority of solitary bees are ground nesting in nature (Vinson and Frankie, 1991; Cane, 1992; Arathi et al.,2017) and identification of their nesting sites is of paramount importance. Remote sensing tools were widely used to track the movement pattern of the bees so that their nesting sites and habitats could be well studied for their domestication. Social bees were reported to be loaded with RFID tags (Radio Frequency Identification) to study their movement pattern, flight distance, hive entries (Streit et al., 2003; Van Geystelen, 2016). Individual native bees could be tagged using sensor tags to identify their foraging area, distance between their habitats and foraging area, peak time of activity of the bees. Designing a sensor tag relevant to the individual bee weight is vital to track the events in a foraging day of an individual bee. Harmonic radars contain a rectifier circuit which generates an echo that equates to one half of the wavelength transmitted. This circuit will be installed in focal individual to be tracked to study its movement Riley et al. 1996 used harmonic radars to track focal bees once they leave their nest to study their flight behaviour. Focal bee of Bombus terrestris audax focal worker bees were tracked by implanting radar transponder in its thorax and number of flights, total time taken for flight in its life time and distance covered during total flight period (Woodgate et al., 2016) was recorded. Osborne et al. (1999) used harmonic radars to study the foraging range and flower constancy of bumble bees. Radars were reported to be efficient in tracking the flight path of bees over greater distances in an accurate manner (Carreck et al., 1999).

Radio telemetry is a widely employed tool in tracking individual bees to study their foraging distance, floral preference, foraging range, habitat preference etc. Vegetation and barriers create shadows areas with which tags are undetectable in radars (Chapman et al., 2011). The presence of uneven topography blocks the solar radiation resulting in lower values of reflectance compared to areas unaffected by shadows (Giles, 2001). The utilization of radio telemetry tools in tracking the movement of individual insects like carpenter bees, beetles, Mormon crickets and migrating dragonflies were reported by researchers (Hedin \& Ranius, 2002;
Sword et al., 2005; Holland et al., 2006). This tool demands greater energy requirement and is widely used in larger sized bees like bumble bees and orchid bees (Wikelski et al., 2010). Incorporating a transmitter in the body of a small sized bees more than its body mass might affect its flight performance. Designing a micro-transmitter suiting to the small body sized bees is the need of the hour so as to track its movement. Micro-radio transmitter was attached to a male orchid bee Exaerete frontalis to track its movement in a complex and forested environment (Wikelski et al., 2010). Radio telemetry tags were used to track the spatio-temporal movements of bumble bees, Bombus terrestris (Hagen et al., 2011).

Under Indian conditions, native Nomiinae bee, Hoplonomia westwoodi is a buzz pollinator of major solanaceous crops like tomato, brinjal causing enhanced fruit and seed set (Amala \& Shivalingaswamy, 2016). The bee prefers to construct its nest in managed mud pots/flower pots in backyard farms with minimal disturbance of soil (Amala \& Shivalingaswamy, 2018). The nesting sites of $H$. westwoodi could be propagated in newer areas by splitting the brood from the mother nest and seeding in newer areas for its augmenting its nesting sites (Amala et al., unpublished data). Identification and tracking its nest to seed in newer areas to increase its abundance might help in enhanced pollination, fruit and seed set of different crops. Designing a battery powered sensor tag for small sized native bees like $H$. westwoodi to track its movement, its nest location might aid in its domestication in artificial trap nests.

\section{Studying bee foraging behaviour}

Active tools like LiDAR (Light Detection and Ranging) helps in predicting bee population mapping and migration pattern in response to change in vegetation type with respect to greenness, water content and photoperiod. It can track large scale movement of individuals without observer bias and to measure bee density across time and space (Hoffman et al., 2007). Vertical looking radars can detect moving bees in flight to assess their size, shape and wing beating frequency (Chapman et al., 2011). Custom made harmonic radars of less weight were used in bumble bees to understand its flight behaviour (Riley, 1989). LiDAR derived maps correlate tree basal area and tree height to derive tree age and to locate the habitats of cavity nesting bees (Martinuzzi et al., 2009). This would help in identifying the habitat suitability for a particular tree for solitary bees for nesting. Time series of landscape data can help to understand how crop phenology affects the abundance and diversity of the bee pollinators in a given habitat. The flowering phenology of tropical tree Tabebuia guayacan was obtained at broader scales using high spatial resolution satellite imagery which was marked by the higher abundance of small and medium sized bees (Sánchez et al., 2011).

\section{Landscape characterization using satellite imagery tools}

Bees target areas with relatively higher floral abundance as different resources increase their foraging efficiency. The 
floral density of a landscape was positively correlated with its nesting preference and foraging pattern of the native bees (Roulston \& Goodell, 2011). Landscape simplification, heterogeneity and fragmentation as a major reason for the decline in pollinator abundance was reported by Boscolo et al. 2017. The two-dimensional images of a landscape cover could be characterized using aerial photography or satellite imagery across spatial as well as temporal scales to assess the suitability of a landscape for pollinator abundance (Strand et al., 2008; Newton et al., 2009). Brosi et al., 2007 reported that an analysis based on satellite imagery and Landsat images revealed nil negative impact of small-scale isolation from forest segments over the bee richness and abundance with relatively higher abundance of stingless bees. The landscape data obtained using these tools not only provides information about the bee's view on a suitability of habitat but also can serve as an advisory tool to the beekeepers to utilize certain areas specifically as foraging sites in a habitat.

\section{Unmanned Aerial Vehicles in mapping floral areas}

Diversification of agricultural landscape is vital in preserving native pollinators to protect their ecosystem services (Landis, 2017). The amount of wild floral resources, type of floral resources and blooming period were positively correlated with the visits of the pollinators (Tuell et al., 2008). Quantification of wildflowers in a large area using manual counts is a challenging task but is a prerequisite to develop conservation strategies for bee pollinators. Mapping the vegetation cover is a crucial step to implement conservation and restoration programmes ( $\mathrm{He}$ et al., 2005). Low resolution satellite imagery has been used over centuries to map the vegetation and to estimate the floral resources across a wider area (Thorp et al., 2011). They are useful in monitoring trends in crop production, monitoring pest and disease incidence but the results are greatly influenced by the prevailing cloud cover (Eberhardt et al., 2016).

Satellite imagery is a passive way of remote sensing that utilizes sensors to measure the energy that is reflected by or emitted from any matter. Though satellite imagery tools were used for long term monitoring of an ecosystem, these tools have few disadvantages that affect their output like limited use of optical sensors during cloudy weather conditions, slow data dissemination, high cost of imagery and delayed initial image acquisition in case of non-pointable sensors. The disadvantage of satellite imagery tools was overcome by the use of unmanned aerial vehicles (UAVs) borne with low weigh sensors with wireless receivers, small on-board global navigational satellite system (GNSS), receivers to provide precise information on vegetation mapping with high resolution (Anderson and Gaston, 2013; Zhang \& Kovacs, 2012). Unmanned aerial vehicles (UAV) borne with sensors along with image processing tools aid in identification and classification of floral resources to predict the occurrence and abundance of pollinators (Lino et al., 2011). Xavier et al. 2018 reported that an UAV equipped with digital camera to capture the images of the floral area and the captures images were subjected supervised image classification to study the correlation between the floral counts and pollinator abundance. High spatial and temporal data especially Photosynthetic active radiation (PAR) and Leaf Area Index (LAR), greening and browning of vegetation will directly help to assess the preference of bees for foraging in an agricultural landscape (Nightingale et al., 2008). Based on the PAR and LAR data, the greenness of plants and trees and their blooming status could be assessed over a period of time to ascertain the availability of foraging sources for the bees (Goward et al., 1995). Greenness of an area is an important factor to study the plant-pollinator interaction. The greenness of target area referred as Normalized Difference Vegetation Index (NDVI) data could be quantified using Advanced Very High-Resolution Radiometer (AVHRR) used simple linear regression slope for each pixel. The data provides information on interannual change rate in green up onset for certain time period which is a crucial data for migratory beekeepers as greenness of an area over a time period directly influence all plant-pollinator interaction (Zhang et al., 2007).

\section{Remote sensing tools in predicting pollination}

Bee visitation although an important tool to measure successful pollination, all the flowers visited by the bees does not guarantee pollination. Boff et al. (2018) reported that high visitation rate of oil bees increased the pollination efficiency of Couepia uiti in Pantanal wetland. Quantification of pollination needs visual manual data collection which involves physical human movement amidst crop canopy in an ecosystem. The mobile insects are highly impacted by the human interferences while floral damage could be frequently encountered (Eckert et al. 2010; Brys \& Jacquemyn, 2012). Remote sensing applications involving automated imaging and classification serves as a viable tool in observing bee visitation enabling better understanding of pollination events (Galbraith et al., 2015). Terrestrial Laser Scanning (TLS) is a ground based active imaging method that utilizes three dimensional variations of the object by comparing it with the sequential terrestrial laser scans (Bauer et al., 2005; Rosser et al., 2005). TLS system generates algorithms to understand the three-dimensional canopy structureswhich is a measure of vegetation structure and floral patch in a given ecosystem for successful pollination (Malhi et al., 2018). Multi temporal images using satellite imagery could measure floral density, pollinator occurrence near the target flowers over a time period. This automated imaging of pollinator density could be correlated with flowering phenology to predict bee visitation rates that in turn could be validated using visual pollinator counts (Suetsugu \& Hayamizu, 2014).

\section{Detection of invasive species}

Invasive exotic bee species pose a potential threat to the native bee fauna by competitive displacement, may 
compete for floral resources, spread pathogenic disease amidst the native fauna causing a loss to native diversity of the bees (Freitas et al., 2009). Invasive bees particularly might compete with native bee fauna for floral resources, thereby disrupting the plant pollinator mutualisms in any ecosystem (Dohzono \& Yokoyama, 2010). Remote sensing tools utilize habitat suitability models to follow the invasive species of bees in temporal and spatial scale to understand the impact of invasive species on native bee fauna.

Tracking of invasive bee species in any ecosystem is vital to prevent the entry and spread of exotic pests and pathogens in the native bee fauna. The spread of infective Trypanosomatid pathogen, Crithidia bombi in Bombus sp. colonies was predicted using spatially explicit model with greater and consistent accuracy by Otterstatter and Thomson (2008). Invasive bee species may compete with nest site requirement of native species and spatially and temporally deplete rewarding resources of native species (Stout \& Morales, 2009). Honeybee species, Apis mellifera scutellata was introduced from South Africa to Brazil for an effort for breeding. The introduced bees escaped containment and bred with European honeybees resulted in hybridization. The "hybridized African honeybees (AHB)" were reported to be more aggressive in behaviour (Franca et al., 1994) with its range expanded gradually to Mexico, California and Florida (Lazaneo, 2002; Szalanski \& Magnus, 2010; Winston, 1992). The further spread and equilibrium range of AHB in United States was studied using satellitederived vegetation phenology data (Nightingale et al., 2008). Jarnevich et al., (2014) used habitat suitability models utilising vegetation covers captured using Moderate Resolution Imaging Spectroradiometer, land surface phenology data to develop Vegetation Continuous Fields (VCF) product to study the distributional range expansion of Africanized honeybees.

\section{Conclusion}

Land-use changes caused by anthropogenic factors attributing to loss of bee pollinators could be easily assessed using remote sensing tools is an unexplored area of research which would help in expansion of bee habitats. Sensor tags and micro-transmitters were widely deployed to study the behaviour of large sized bees and other insects (Pasquet et al., 2008; Wikelski et al., 2006) where there is a need to design suitable remote sensing-based tags to track small or medium sized native buzz pollinating bees like $H$. westwoodi, Amegilla zonata to conserve their habitats and to study their foraging pattern and movement between different crops. There is a vital need for the collaborative research between the pollination ecologists and remote sensing experts to devise suitable tools to monitor pollinators in cropping ecosystems for their conservation and utilization.

\section{References}

Amala, U., \& Shivalingaswamy, T.M. (2018). Nesting biology, seasonality and host range of sweat bee, Hoplonomia westwoodi (Gribodo) (Hymenoptera: Halictidae: Nomiinae), Sociobiology, 65(3): 491-496.

Anderson, K., \& Gaston, K.J. (2013). Lightweight unmanned aerial vehicles will revolutionize spatial ecology. Frontiers in Ecology and the Environment, 11: 138-146.

Arathi, H.S., Davidson, D. \& Mason, L. (2017). Attracting native bees to your landscape. Extension Folder, Colorado State University, https://extension.colostate.edu/docs/pubs/insect/ 05615.pdf

Bauer, A., Paar, G., \& Kaltenbock, A. (2005). Mass Movement Monitoring Using Terrestrial Laser Scanner for Rock Fall Management, in: Geo-information for Disaster Management, edited by: van Oosterom, P., Zlatanova, S., and Fendel, E. M., Springer, Berlin, 393-406.

Boff, S., Melo-de-pinna, G.F.A., Pott, A. \& Araujo, A.C. (2018). High visitation rate of oil bees may increase pollination efficiency of Couepiauiti in Pantanal wetland. Apidologie doi: 10.1007/s13592-018-0598-7.

Boscolo, D., Tokumoto, P.M., Ferreira, P.A., Ribeiro, J.W. \& Dos Santos, J.S. (2017). Positive responses of flower visiting bees to landscape heterogeneity depend on functional connectivity levels. Perspectives in Ecology and Conservation, 15(1):18-24.

Brosi, B.J., Daily, G.C., Shih, T.M., Oviedo, F., \& Durán, G. (2007). The effects of forest fragmentation on bee communities in tropical countryside. Journal of Applied Ecology, 45:773-83.

Brown, M.J.F., \& Paxton, R.J. (2009). The conservation of bees: a global perspective. Apidologie, 40:410-6.

Brys, R. \&Jacquemyn, H. (2012). Effects of human-mediated pollinator impoverishment on floral traits and mating patterns in a short-lived herb: an experimental approach. Functional Ecology 26: 189-197.

Chapman, J.W., Drake, V.A., \& Reynolds, D.R. (2011). Recent insights from radar studies of insect flight. Annual Review of Entomology, 56:337-56.

Cane, J.H. (1992). Soils of ground nesting bees (Hymenoptera: Apoidea): texture, moisture, cell depth and climate. Journal of the Kansas Entomological Society, 64: 406-413.

Carreck, N.L., Osborne, J.L., Capaldi, E.A., Riley, J.R. (1991). Tracking bees with radar. Bee World, 80(3): 124-131.

Diao, C., \& Wang, L. (2014). Development of an invasive species distribution model with fine-resolution remote sensing. International Journal of Applied Earth Observation and Geoinformation, 30:65-75.

Dohzono, I., \& Yokoyama, J. (2010). Impacts of alien bees on native plant-pollinator relationships: a review with special emphasis on plant reproduction. Applied Entomology and Zoology, 45:37-47.

Dong, J., Kaufmann, R.K., Myneni, R.B., Tucker, C.J., Kauppi, P.E., Liski, J., Buermann, W., Alexeyev, V., \& Hughes, M.K. 
(2003). Remote sensing estimates of boreal andtemperate forest woody biomass: carbon pools, sources, and sinks. Remote Sensing of Environment, 84(3):393-410.

Eckert, C.G., Kalisz, S., Geber, M.A., Sargent, R., Elle, E., Cheptou P-O, Goodwillie C., Johnston, M.O., Kelly, J.K., Moeller, D.A., Porcher, E., Ree, R.H., Vallejo-Marin M. \& Winn A. (2010). Plant mating systems in a changing world. Trends in Ecology and Evolution, 25: 35-43.

Eberhardt, I.D.R., Schultz, B., Rizzi, R., Sanches, I.D.A., Formaggio, A.R., Atzberger, C., Mello, M.P., Immitzer, M., Trabaquini, K., \& Foschiera, W. (2016). Cloud cover assessment for operational crop monitoring systems in tropical areas. Remote Sensing, 8: 219.

Freitas, B.M., Imperatriz-Fonseca, V.L., Medina, L.M., Kleinert, A.M.P., Galetto, L., Parra G.N., \& Euan, J.J.E.Q. (2009). Diversity, threats and conservation of native bees in the Neotropics. Apidologie, 40:332-46.

Franca, F.O.S., Benvenuti, L.A., Fan, H.W., Santos, D., Hain, S.H. \& Picchi-Martins, F.R. (1994). Severe and fatal mass attacks by 'killer' bees (Africanized bees-Apis mellifera scutellata) in Brazil: clinicopathological studies with measurements of serum venom concentrations. QJM: An International Journal of Medicine, 87: 269-282.

Galbraith, S.M., Vierling, L.A. \& Bosque-Pérez, N.A. (2015). Remote Sensing and ecosystem services: current status and future opportunities for the study of bees and pollinationrelated services. Current Forestry Reports, 1: 261. doi: 10.1007/ s40725-015-0024-6

Giles, P.T. (2001). Remote sensing and cast shadows in mountainous terrain. Photogrammetric Engineering and Remote Sensing, 67(7):833-839.

Hagen, M., Wikelski, M., \& Kissling, W.D. (2011). Space use of bumblebees (Bombus spp.) revealed by radio-tracking. PLoS ONE, 6(5): e19997. doi: 10.1371/journal.pone.001999

Hedin, J. \& Ranius. T. (2002). Using radio telemetry to study dispersal of the beetle Osmoderma eremita, an inhabitant of tree hollows. Computers and Electronics in Agriculture 35: 171-180.

He, C., Zhang, Q., Li, Y., Li, X. \& Shi, P. (2005). Zoning grassland protection area using remote sensing and cellular automata modelling - A case study in Xilingol steppe grassland in northern China. Journal of Arid Environments, 63(4): 814-826.

Hoffman, D.S., Nehrir, A.R., Repasky, K.S., Shaw, J.A., \& Carlsten, J.L. (2007). Range-resolved optical detection of honeybees by use of wing-beat modulation of scattered light for locating land mines. Applied Optics, 46:3007-12.

Holland, R.A., Wikelski, M. \&Wilcove, D.S. (2006) How and why do insects migrate? Science 313: 794-796.

Jarnevich, C.S., Esaias, W.E., Ma, P.L.A., Morisette, J.T., Nickeson, J.E., Stohlgren, T.J., Holcombe, T.R., Nightingale, J.M., Wolfe, R.E. \& Tan, B. 2014. Regional distribution models with lack of proximate predictors: Africanized honeybees expanding north. Diversity and Distributions, 20: 193-201.

Kimura, T., Ohashi, M., Crailsheim, K., Schmickl,T., Okada, R., Radspieler, G. \& Ikeno, H. (2014). Development of a new method to track multiple honey bees with complex behaviors on a flat laboratory arena. PLosOne. doi: 10.1371/journal. pone. 0084656

Klein, A.M., Vaissiere, B.E., Cane, J.H., Steffan-Dewenter, I., Cunningham, S.A., Kremen, C., \& Tscharntke, T. (2007). Importance of pollinators in changing landscapes for world crops. Proceedings of the Royal Society B: Biological Sciences, 274(1608):303-313.

Kremen, C., Williams, N.M., Aizen, M.A., Gemmill-Herren, B., LeBuhn, G. \& Minckley, R. (2007). Pollination and other ecosystem services produced by mobile organisms: a conceptual framework for the effects of land-use change. Ecology Letters, 10:299-314.

Landis, D.A. (2017). Designing agricultural landscapes for biodiversity-based ecosystem services. Basic and Applied Ecology, 18: 1-12.

Lazaneo V. (2002). Bee Alert: Africanized Honey Bee Facts. University of California- Agriculture and Natural Resources. Publication 8068

Lino, A.C.L., Sanches, J., Moraes, G., Dias-Tagliacozzo, I., Augusto, F., Lima, B. \& Nascimento, T.S. (2011). Flower classification supported by digital imaging techniques. Journal of Information Technology in Agriculture, 4: 1-6.

Martinuzzi, S., Vierling, L.A., Gould, W.A., Falkowski, M.J., Evans, J.S., Hudak, A.T., \& Vierling, K.T. (2009). Mapping snags and understory shrubs for a LiDAR-based assessment of wildlife habitat suitability. Remote Sensing of Environment, 113:253-346.

Malhi, Y., Jackson, T., Patrick Bentley, L., Lau, A., Shenkin, A., Herold, M., Calders, K., Bartholomeus, H. \& Disney, M.I. (2018). New perspectives on the ecology of tree structure and tree communities through terrestrial laser scanning. Interface Focus, 8: 20170052. doi: 10.1098/rsfs.2017.0052

Mulla, D.J. (2013). Twenty five years of remote sensing in precision agriculture: key advances and remaining knowledge gaps. Biosystems Engineering, 114(4):358-371.

Newton, A.C., Hill, R.A., Echeverria, C., Golicher, D., Rey, Benayas, J.M., Cayuela L., \& Hinsley, S.A. (2009). Remote sensing and the future of landscape ecology. Progress in Physical Geography: Earth and Environment, 33:528-46.

Nightingale, J.M., Esaias, W. E., Wolfe, R.E., Nickeson, J.E., \& Ma, P.L. (2008). Assessing Honey Bee Equilibrium Range and Forage Supply using Satelite-Derived Phenology. In Geoscience and Remote Sensing Symposium, 2008. IGARSS 2008. IEEE International (Vol. 3, pp. III-763). IEEE.

Ollerton, J., Winfree, R., \& Tarrant, S. (2011). How many 
flowering plants are pollinated by animals? Oikos, 120: 321-326.

Osborne, J.L., Clark, S.J., Morris, R.J., Williams, I.H., Riley, J.R., Smith, A.D., Reynolds, D. R., \& Edwards, A.S. (1999). A landscape-scale study of bumble bee foraging range and constancy, using harmonic radar. Journal of Applied Ecology, 36: 519-533.

Otterstatter M.C. \& Thomson J.D. (2008). Does pathogen spill over from commercially reared bumble bees threaten wild pollinators? PLoS Biology, 3:1-9.

Pasquet, R.S., Peltier, A., Hufford, M.B., Oudin, E. \& Saulnier J. (2008). Long-distance pollen flow assessment through evaluation of pollinator foraging range suggests transgene escape distances. Proceedings of National Academy of Sciences of USA, 105: 13456-13461.

Peh, K.S.H., \& Lewis, S. L. (2012). Conservation implications of recent advances in biodiversity - Functioning research. Biological Conservation, 151:26-31.

Potts, S.G., Biesmeijer, J.C., Kremen, C., Neumann, P., Schweiger, O., \& Kunin, W.E. (2010). Global pollinator declines: trends, impacts and drivers. Trends in Ecology \& Evolution, 25:345-53.

Riley, J.R. (1989). Remote sensing in entomology. Annual Review of Entomology, 34:247-71.

Rader, R., Reilly, J., Bartomeus, I., \& Winfree, R. (2013). Native bees buffer the negative impact of climate warming on honey bee pollination of watermelon crops. Global Change Biology, doi: 10.1111/gcb.12264

Riley, J. R., Smith, A.D., Reynolds, D.R., Edwards, A.S., Osborne, J.L., Williams, I.H., Carreck, N. L. \& Poppy, G. M. (1996). Tracking bees with harmonic radar. Nature,379:29-30

Rosser, N. J., Petley, D. N., Lim, M., Dunning, S. A., \& Allison, R. J. (2005). Terrestrial laser scanning for monitoring the process of hard rock coastal cliff erosion, Quarterly Journal of Engineering Geology and Hydrogeology, 38(4): 363-375.

Roulston, T.H. \& Goodell, K. (2011). The role of resources and risks in regulating wild bee populations. Annual Review of Entomology, 56:293-312.

Sanchez Azofeifa, A., Rivard, B., Wright, J., Feng, J.L., Li, P., Chong, M.M., \& Bohlman, S.A. (2011). Estimation of the distribution of Tabebuia guayacan (Bignoniaceae) using highresolution remote sensing imagery. Sensors, 11:3831-51.

Strand, E.K., Vierling, L.A., Smith, A.M.S., \& Bunting, S.C. (2008). Net changes in aboveground woody carbon stock in western juniper woodlands, 1946-1998. Journal of Geophysical Research, 113:1-13.

Stout, J.C. \& Morales, C.L. (2009). Ecological impacts of invasive alien species on bees. Apidologie, 40: 388-409.

Streit S., Block F., Pirk W.W. \& Tautz J. (2003). Automatic Life-Long Monitoring of Individual Insect Behaviour Now Possible. Zoology, 106:169-171.
Suetsugu, K., \& Hayamizu M. (2014). Moth floral visitors of the three rewarding Platanthera orchids revealed by interval photography with a digital camera. Journal of Natural History, 48:1103-1109.

Szalanski, A.L. \& Magnus, M.M. (2010). Mitochondrial DNA characterization of Africanized honey bee (Apis mellifera) populations from the USA. Journal of ApiculturalResearch 49: $177-185$.

Thorp, K., \& Dierig, D. (2011). Color image segmentation approach to monitor flowering in lesquerella. Industrial Crops and Products, 34: 1150-1159.

Tuell, J.K., Fiedler, A.K., Landis, D., \& Isaacs, R. (2008). Visitation by wild and managed bees (Hymenoptera: Apoidea) to Eastern U.S. Native plants for use in conservation programs. Environmental Entomology, 37: 707-718.

Van Geystelen A., Benaets K., de Graaf D.C., Larmuseau M. \& Wenseleers T. (2016). Track-a-Forager: A program for the automated analysis of RFID tracking data to reconstruct foraging behaviour. Insectes Sociaux. 63:175-183. doi: 10.10 07/s00040-015-0453-z.

Vinson, S.B., \& Frankie, G.W. (1991). Nest variability in Centris aethyctera (Hymenoptera: Anthophoridae) in response to nest site conditions. Journal of the Kansas Entomological Society, 64: 156-162.

Wikelski, M., Moskowitz, D., Adelman, J.S., Cochran, J., Wilcove, D.S. \& May, M.L. (2006) Simple rules guide dragonfly migration. Biology Letters, 2: 325-329.

Wikelski, M., Moxley, J., Eaton-Mordas, A., López-Uribe, M.M., Holland, R., Moskowitz, D., Roubik, D.W., \& Kays, R. (2010). Large-range movements of neotropical orchid bees observed via radio telemetry. PLoS One, 5:5-10.

Winfree R. (2013). Global change, biodiversity, and ecosystem services: what can we learn from studies of pollination? Basic and Applied Ecology,14:453-60.

Winston, M.L. (1992). The biology and management of africanized honey bees. Annual Review of Entomology, 37: 173-193.

Woodgate, J.L., Makinson, J.C., Lim, K.S., Reynolds, A.M. \& Chittka, L. (2016). Life-Long radar tracking of bumblebees. PlosOne. doi: 10.1371/journal.pone.0160333

Xavier, S.S., Coffin, A.W., Olson, D.M., \& Schmidt, J.M. (2018). Remotely estimating beneficial arthropod populations: implications of a low-cost small unmanned aerial system. Remote Sensing, 10(9): 1485.

Zhang, X., Tarpley, D. \& Sullivan, J. (2007). Diverse responses of vegetation phenology to a warming climate. Geophysical Research Letters: 34, doi: 10.1029/2007GL031447.

Zhang, C., \& Kovacs, J.M. (2012). The application of small unmanned aerial systems for precision agriculture: A Review. Precision Agriculture, 13: 693-712. 